OPEN ACCESS

Edited by:

Zhongtang Yu,

The Ohio State University,

United States

Reviewed by:

Suzanne Lynn Ishaq,

University of Oregon, United States

David R. Yanez-Ruiz,

Consejo Superior de Investigaciones

Cientificas (CSIC), Spain

${ }^{*}$ Correspondence:

Xinyan Han

xyhan@zju.edu.cn

tThese authors have contributed equally to this work and

co-first authors.

Specialty section: This article was submitted to Microbial Symbioses,

a section of the journal

Frontiers in Microbiology

Received: 18 July 2017 Accepted: 21 December 2017

Published: 09 January 2018

Citation:

Hu L, Geng S, Li Y, Cheng S, Fu X,

Yue $X$ and $\operatorname{Han} X$ (2018) Exogenous

Fecal Microbiota Transplantation from Local Adult Pigs to Crossbred

Newborn Piglets.

Front. Microbiol. 8:2663.

doi: 10.3389/fmicb.2017.02663

\section{Exogenous Fecal Microbiota Transplantation from Local Adult Pigs to Crossbred Newborn Piglets}

\author{
Luansha Hu+, Shijie Geng ${ }^{\dagger}$, Yuan Li, Saisai Cheng, Xiongfeng Fu, Xiaojing Yue and \\ Xinyan Han*
}

Key Laboratory of Animal Nutrition and Feed Science in East China, Ministry of Agriculture, College of Animal Science, Zhejiang University, Hangzhou, China

This study was conducted to investigate the effect of exogenous fecal microbiota transplantation on gut bacterial community structure, gut barrier and growth performance in recipient piglets. Twelve litters of Duroc $\times$ Landrace $\times$ Yorkshire piglets of the same birth and parity were weighed and divided into two groups. One group (recipient piglets) was inoculated orally with fecal microbiota suspension of healthy adult Jinhua pigs daily from day 1 to day 11 . The other (control) was given orally the same volume of sterile physiological saline at the same time. The experiment lasted 27 days. The results showed that the relative abundance of Firmicutes, Prevotellaceae, Lachnospiraceae, Ruminococcus, Prevotella, and Oscillospira in the colon of recipient piglets was increased. Proteobacteria, Fusobacteriaceae, Clostridiaceae, Pasteuriaceae, Alcaligenaceae, Bacteroidaceae, Veillonellaceae, Sutterella, Escherichia, and Bacteroides in the colon of recipient piglets were decreased. An average daily weight gain of recipient piglets was increased, and diarrhea incidence of the recipient was decreased during the trial. Intestinal morphology and tight junction barrier of recipient piglets were improved. The optical density of slgA ${ }^{+}$cells, the number of goblet cells and relative expressions of MUC2 in the intestinal mucosa of recipient piglets were enhanced. Protein expressions of $\beta$-defensin 2 and mRNA expressions of TLR2 and TLR4 in the intestinal mucosa of recipient piglets were also increased. These findings supported that the exogenous fecal microbiota had significant effects on animal's growth performance, intestinal barrier function, and innate immune via modulating the composition of the gut microbiota.

Keywords: exogenous fecal microbiota transplantation, gut microbiota, intestinal morphology, intestinal barrier function, newborn piglets

\section{INTRODUCTION}

Intestinal microbial flora plays an important role in human and animal health, it has attracted more and more attention in recent years. Gut contains a tremendous amount of microorganisms, which makes a very big contribution to individual health. A healthy human intestine contains more than $10^{14}$ bacteria, which is 10 times the number of all cells in the body (Koboziev et al., 2014). As it has a close relationship with absorption of nutrients, colonization resistance, development of the immune system and other functions in host, intestinal microbial flora is known as an essential 
organ (Moya and Ferrer, 2016). Although gut microbiota resides in the intestine, it can cause systemic effects (Ho et al., 2015). Not only the intestine got affected by the change of gut microbiota diversity and balance, but the whole body system could get changed (Ho et al., 2015). Diseases caused by imbalance of intestinal microbiota can be treated by treatments involving microbiota, such as probiotics, prebiotics, synbiotics, and FMT (fecal microbiota transplantation) (Ho et al., 2015). FMT refers to the transplantation of fecal suspension from healthy individuals into the gastrointestinal tract of the patient, in order to achieve the treatment of gastrointestinal diseases. The first record about FMT was a Chinese physician named Ge Hong who used FMT to treat food poisoning and severe diarrhea in Jin Dynasty, so far, the medical profession has never stopped exploration and application of FMT technology. The first randomized controlled trial of FMT was reported in 2012, in contrast to vancomycin, infusion of donor fecal bacteria was significantly more effective in treating refractory recurrent Clostridium difficile infection (van Nood et al., 2013). In addition, it also became a tool for functional "knock-in" studies of the microbiota in animal models (Bojanova and Bordenstein, 2016). However, the connections between FMT, the structural changes of gut microbiota and improvements of intestinal health in recipients as well as the mechanism underlying these effects are not fully illustrated.

Intestinal microbiota of a newborn is in an unstable state, its diversity increase gradually and is vulnerable to external environment and other factors (Clemente et al., 2012; Pabst et al., 2016). Therefore, newborn piglets are usually used as a model, which can be a good animal model for studying human nutrition and physiology (Puiman and Stoll, 2008; Merrifield et al., 2011). However, pig diarrhea can cause sucking piglets to die, which would bring significant economic losses to the pig farm. Jinhua pig, one of the most well-known local breeds in China, has the advantages of good meat quality, high rate of reproduction and a better ability to resist the challenge of enterotoxigenic Escherichia coli (ETEC) K88 and maintain the intestinal physiology homeostasis (Gao et al., 2013). At the present study, newborn piglets were selected as the model, to explore the effect of exogenous fecal microbiota on animal health from the perspective of gut microbiota, intestinal physiological function and growth performance. We hypothesized that exogenous fecal microbiota transplantation would modulate the structure of the gut microbiota, improve intestinal barrier and immune function in newborn piglets. Therefore, this study might provide novel insights in understanding this efficient therapy strategy for various gastrointestinal diseases.

\section{MATERIALS AND METHODS}

\section{Preparation of Fecal Microbiota Suspension of Donor Pigs}

Jinhua pigs with no antibiotics treated within 3 months were used in this experiment as fecal donors. The detection of hog cholera virus, porcine circovirus-2, porcine reproductive, and respiratory syndrome virus, pseudorabies virus, foot and mouth disease virus, swine erysipelas, Mycoplasma hyopneumoniae in donor pigs were negative. The fecal suspension was prepared as described by Pang et al. (2007), which was quickly aspirated and transferred to sterile Eppendorf tubes and stored at $-80^{\circ} \mathrm{C}$.

\section{Transplantation of Fecal Microbiota Experiment and Animal Management}

The present study followed the institutional and national guidelines for the care and use of animals. All animal management experimental procedures involving animal care and sampling were approved by the Animal Care and Use Committee of Zhejiang University. A total of twelve litters (9-10 piglets per litter) of DLY(Duroc $\times$ Landrace $\times$ Yorkshire) piglets of the same birth day and parity were weighed and divided into two groups from birth(each group had six pens with two pigs per pen). One group (recipient piglets) was inoculated orally with $1.5 \mathrm{ml}$ fecal suspension daily from day 1 to day 11 . The other (control) was given orally the same volume of sterile physiological saline at the same time. All piglets were breast-fed by sows and weaned at day 28. All of the piglets were inoculated orally using a syringe attached to a polyethylene tube at $6 \mathrm{am}$ in the morning. The two groups were kept in two separate pig houses. And the conditions (temperature, humidity and other conditions) of the two pig houses were controlled consistently. The experiment lasted 27 days. Six piglets were randomly selected from each group and euthanized by sodium pentobarbital $(50 \mathrm{mg} / \mathrm{kg}$ body weight) at day 12 and day 27. Piglets were weighed individually at the start and end of the experiment, and average daily gain (ADG) was calculated for both groups. The number of piglets with diarrhea and its duration were observed and recorded during the experiment. Diarrhea was defined as liquid consistency over a minimum of 2 consecutive days. The incidence of diarrhea (\%) was calculated as the total number of diarrheal piglets during the period divided by the total number of piglets multiplies duration of the trial.

\section{Collections of Samples}

Intestinal samples and colon contents were collected when the piglets were euthanized. For intestinal morphological analysis, the duodenal (about $5 \mathrm{~cm}$ from the pyloric-duodenal junction), mid-jejunal and ileal (about $10 \mathrm{~cm}$ from the ileal-caecal junction) segments were sampled and fixed in buffered formalin (10\%) at $4^{\circ} \mathrm{C}$ for morphometric analysis. Jejunum tissues were fixed overnight in a $2.5 \%$ glutaraldehyde solution at $4^{\circ} \mathrm{C}$ and then these samples were treated for observation by electron microscopy. The mucosa samples from the ileum and colon were harvested by scraping with a sterile glass microscope slide, rapidly frozen in liquid nitrogen and stored at $-80^{\circ} \mathrm{C}$ for further analysis. Colon contents (from the middle of the colon) were collected from piglets. Digesta samples were placed into sterile polypropylene centrifuge tubes, snap frozen in liquid nitrogen and kept frozen at $-80^{\circ} \mathrm{C}$ until DNA extraction.

\section{Extraction of DNA and 16S rRNA Amplicon Sequencing}

Total DNA was extracted and purified from about $200 \mathrm{mg}$ of individual colon contents using the QIAamp stool DNA Mini 
kit (QIAGEN, United States) according to the manufacturer's instructions. Sequencing was performed at the Novogene Bioinformatics Technology Co. Ltd., Beijing, China. DNA was amplified by using the 515f/806r primer set (515f:5'-GTG CCA GCM GCC GCG GTA A-3', 806r:5'-XXX XXX GGA CTA CHV GGG TWT CTA AT- $3^{\prime}$ ). PCR reactions were carried out in $30 \mu \mathrm{L}$ reactions with $15 \mu \mathrm{L}$ of Phusion ${ }^{\circledR}$ High-Fidelity PCR Master Mix (New England Biolabs); $0.2 \mu \mathrm{M}$ of forward and reverse primers, and about 10 ng template DNA. Thermal cycling consisted of initial denaturation at $98^{\circ} \mathrm{C}$ for $1 \mathrm{~min}$, followed by 30 cycles of denaturation at $98^{\circ} \mathrm{C}$ for $10 \mathrm{~s}$, annealing at $50^{\circ} \mathrm{C}$ for $30 \mathrm{~s}$, and elongation at $72^{\circ} \mathrm{C}$ for $30 \mathrm{~s}$. Finally $72^{\circ} \mathrm{C}$ for $5 \mathrm{~min}$. PCR products were purified by using the QIAquick Gel Extraction Kit (QIAGEN, Dusseldorf, Germany). Sequencing libraries were generated using NEB Next ${ }^{\circledR}$ Ultra $^{\mathrm{TM}}$ DNA Library Prep Kit for Illumina (NEB, United States) following manufacturer's recommendations and index codes were added. The library quality was assessed on the Qubit@2.0 Fluorometer (Thermo Scientific) and Agilent Bioanalyzer 2100 system. At last, the library was sequenced on an Illumina HiSeq platform and $250 \mathrm{bp}$ paired-end reads were generated.

\section{Examination of Intestinal Morphological}

The samples were embedded with paraffin wax and sectioned at $5 \mu \mathrm{m}$ on a rotary microtome. Then, the sections were stained with hematoxylin and eosin. Villus height and crypt depth (V/C) were evaluated under a light microscope using a 1/100 ocular scale (Olympus, Japan). Morphological indices were determined using image processing and analysis system (Version 1, Leica Imaging Systems Ltd., Cambridge, United Kingdom) according to the technique of Han et al. (2014).

The mid-jejunum specimen fixed with $2.5 \%$ glutaraldehyde was washed with phosphate buffer three times, then fixed with $1 \% \mathrm{OsO}_{4}$ solution in ( $\left.\mathrm{pH} 7.0\right)$ for $2 \mathrm{~h}$ and washed with phosphate buffer $(0.01 \mathrm{M})$ three times. After that, the specimens were dehydrated by a graded series of ethanol $(30,50,70,80,90$, and $95 \%$ respectively). The segments were transferred to the mixture of alcohol and iso-amyl acetate (v:v = 1:1) for $30 \mathrm{~min}$, and then transferred to iso-amyl acetate (100\%) for $1 \mathrm{~h}$. After being dehydrated with liquid $\mathrm{CO}_{2}$ by a critical point dryer (Hitachi Model HCP-2, Japan), the segments were coated with goldpalladium and observed by Scanning Electron Microscope (SEM, Philips Model TM-1000, Japan).

\section{Relative Expression of mRNA by Real-time PCR}

The mRNA levels of TLR2, TLR4, and MUC2 were determined by real-time PCR. Total RNA was extracted from ileum and colon mucosa using the TRIzol ${ }^{\circledR}$ Plus RNA Purification Kit following the manufacturer's guidelines. RNA was spectrophotometrically quantified and its integrity was verified by agarose gel electrophoresis. Reverse transcription using the SuperScript ${ }^{\text {TM }}$ III First-Strand Synthesis SuperMix for qRT-PCR was carried out following the manufacturer's instructions. Quantitative analysis of PCR was carried out on a CFX384 real-time fluorescent quantitative PCR system using a Power SYBR ${ }^{\circledR}$ Green PCR Master Mix, according to the manufacturer's instructions. The primers used were presented in Table 1. Each sample was repeated three times and the relative expression level of each gene was analyzed statistically by $2^{-\Delta \Delta C_{\mathrm{T}}}$ (Livak and Schmittgen, 2001).

\section{Relative Expression of Protein by Western Blot}

The protein expressions of $\beta$-defensin 2, MUC2, tight junction proteins: $\mathrm{ZO}-1$ and Occludin in the intestine were determined by western blot. Total protein extraction was performed using T-PER Tissue Protein Extraction Reagent (Thermo Pierce, 78510), protein quantification was then performed using the BCA Quantitation Kit. After the process of SDS-page electrophoresis analysis, transferred membranes, T-TBS (containing 5\% nonfat dry milk or BSA) was added to the membrane and blocked at room temperature for $1 \mathrm{~h}$. Antibody (1: 100) was added and incubated overnight at $4^{\circ} \mathrm{C}$, then washing the membrane. Secondary antibody [Goat anti-Mouse $\operatorname{IgG}(\mathrm{H}+\mathrm{L})]$ was added and incubated at room temperature for $1 \mathrm{~h}$, and then washed the membrane. SuperSignal ${ }^{\circledR}$ West Dura Extended Duration Substrate was used for Western blot detection. The optical density of the bands was analyzed using Image J software. The $\beta$-actin was used as an internal control, which exhibited no difference between the groups. The relative abundance of each target protein was expressed as the ratio of target protein $/ \beta$-actin protein.

\section{Detection of Goblet Cells and slgA ${ }^{+}$Cells}

The morphology and distribution of goblet cells in the intestinal epithelium were observed by light microscopy after the wax were stained with PAS according to the procedures

TABLE 1 | Real-time PCR primers and conditions.

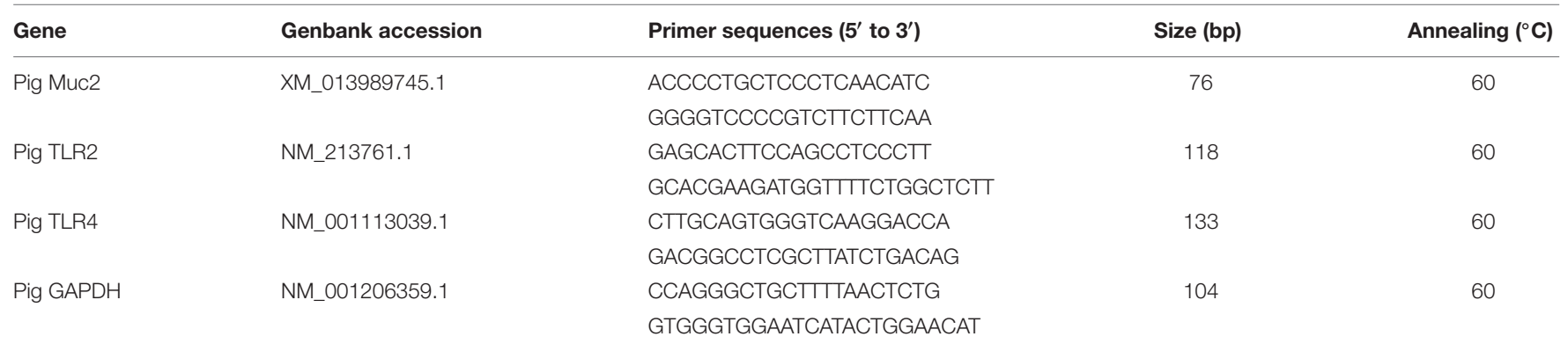


TABLE 2 | The alpha diversity index of intestinal microflora in piglets.

\begin{tabular}{|c|c|c|c|c|c|}
\hline \multirow[t]{2}{*}{ Items } & \multicolumn{3}{|c|}{ Day 12} & \multicolumn{2}{|c|}{ Day 27} \\
\hline & JH & Control piglets & Recipient piglets & Control piglets & Recipient piglets \\
\hline OTU & 843 & $824 \pm 248$ & $791 \pm 226$ & $1052 \pm 334$ & $1243 \pm 378$ \\
\hline Chao 1 & 1201 & $917 \pm 128$ & $897 \pm 190$ & $1214 \pm 225$ & $1342 \pm 292$ \\
\hline Shannon & 6.6 & $7.2 \pm 1.2$ & $7.0 \pm 0.8$ & $7.3 \pm 1.0$ & $8.0 \pm 1.8$ \\
\hline
\end{tabular}

of van Es et al. (2005). Moditec camera software was applied to take pictures. 5-10 complete intestine villi were selected from each tissue slice, and the number of goblet cells of per 100 intestinal epithelial cells was counted. Moreover, ileum and colon tissue sections were stained by immunohistochemical method according to the procedures of (Xiao et al., 2013). The average integrated optical density of $\operatorname{sgA}^{+}$cells in the ileum and colon mucosa was detected by using an image analysis system.

\section{Statistics}

According to the Barcode sequence and the PCR amplification primer sequence, the sample data were separated from the downmachine data, and the Barcode and primer sequences were cut off using FLASH (V1.2.7) ${ }^{1}$. The original Tags data (Raw Tags) was obtained after the sample was spliced. The spliced Raw Tags, need to undergo a rigorous filtering to get high quality Tags (Clean Tags). Refer to Qiime (V1.7.0)2 ${ }^{2}$, the flow of Tags Quality Control, the procedure as follows: (a) acquirement of Tags: The Raw Quality was cut off at the first low mass base from the continuous low mass (the default quality threshold was $\leq 19$ ) to the set length (default length value was 3 ). (b) The length filter of Tags: Further filtering out the value of which the continuous high quality base length is less than $75 \%$ of the length of the interceptive Tags. The sequences were clustered

${ }^{1}$ http://ccb.jhu.edu/software/FLASH/

${ }^{2} \mathrm{http}: / /$ qiime.org/scripts/split_libraries_fastq.html into OTUs (Operational Taxonomic Units) with 97\% consistency, and a representative sequence of OTUs was selected. Species annotation of OTUs representative sequences was performed with RDP Classifier method and Green Gene database. The Alpha diversity analysis included Shannon index and Chao1. Data were analyzed using the SAS statistical package (SAS Institute, Cary, NC, United States). Heatmaps were visualized using the $\mathrm{R}$ software, log 10 -transformation was applied on the bacterial relative abundance data matrix. Data are expressed as the mean \pm SEM, and all mean values were tested using Student's $t$-test. A value of $P<0.05$ was considered statistically significant.

\section{RESULTS}

\section{S rRNA Analysis of Bacterial Communities}

The information of OTU number and alpha diversity indexes of intestinal microbiota in piglets is presented in Table 2. There was no significant difference in OTU number, Shannon and Chaol index between the recipient piglets and control piglets both on days 12 and $27(P>0.05)$. Relative abundance of gut microbial composition in the level of phylum was shown in Figure 1. The gut microbiotas of all pigs were dominated by Firmicutes, Bacteroidetes, Proteobacteria, and Fusobacteria. Firmicutes and Bacteroides accounted for 89-98\% and were the absolute superiority in gut microbial flora composition of
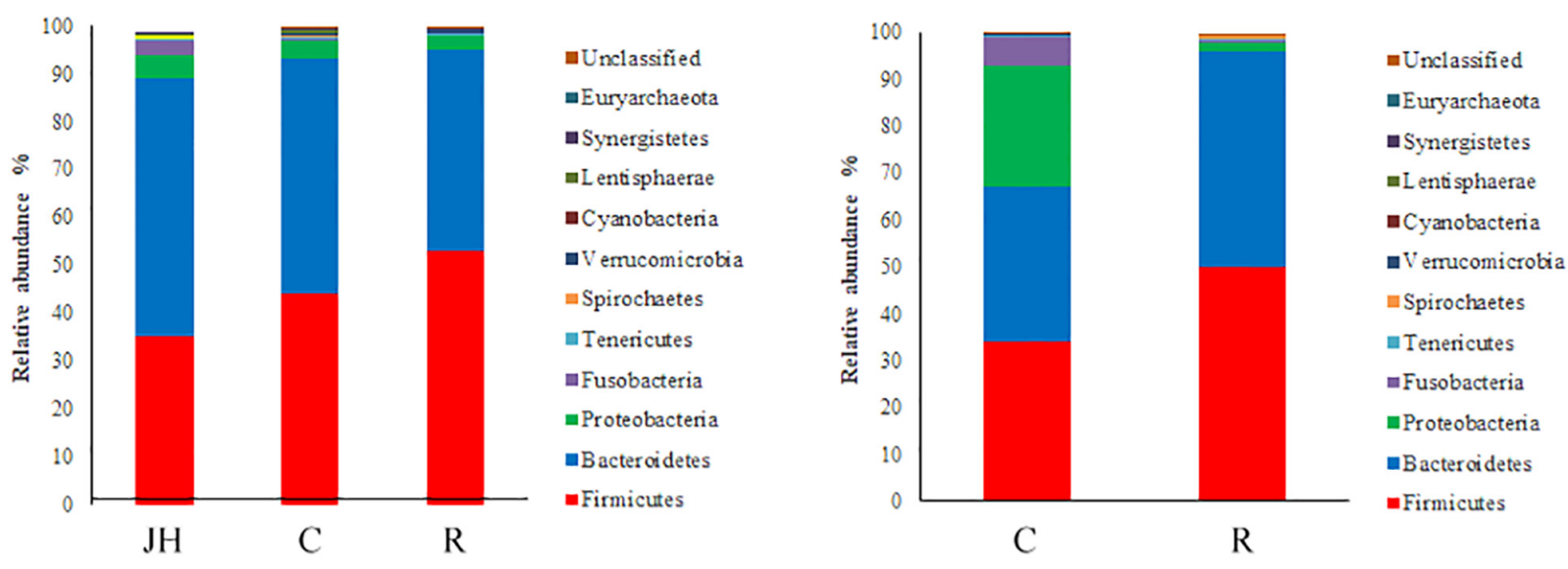

FIGURE 1 | 16S rRNA gene analysis revealed the colonic bacterial community structure of piglets orally treated with or without exogenous fecal microflora (relative abundance of microflora in the level of phylum.) JH, Jinhua pigs. C, Control piglets. R, Recipient piglets. 

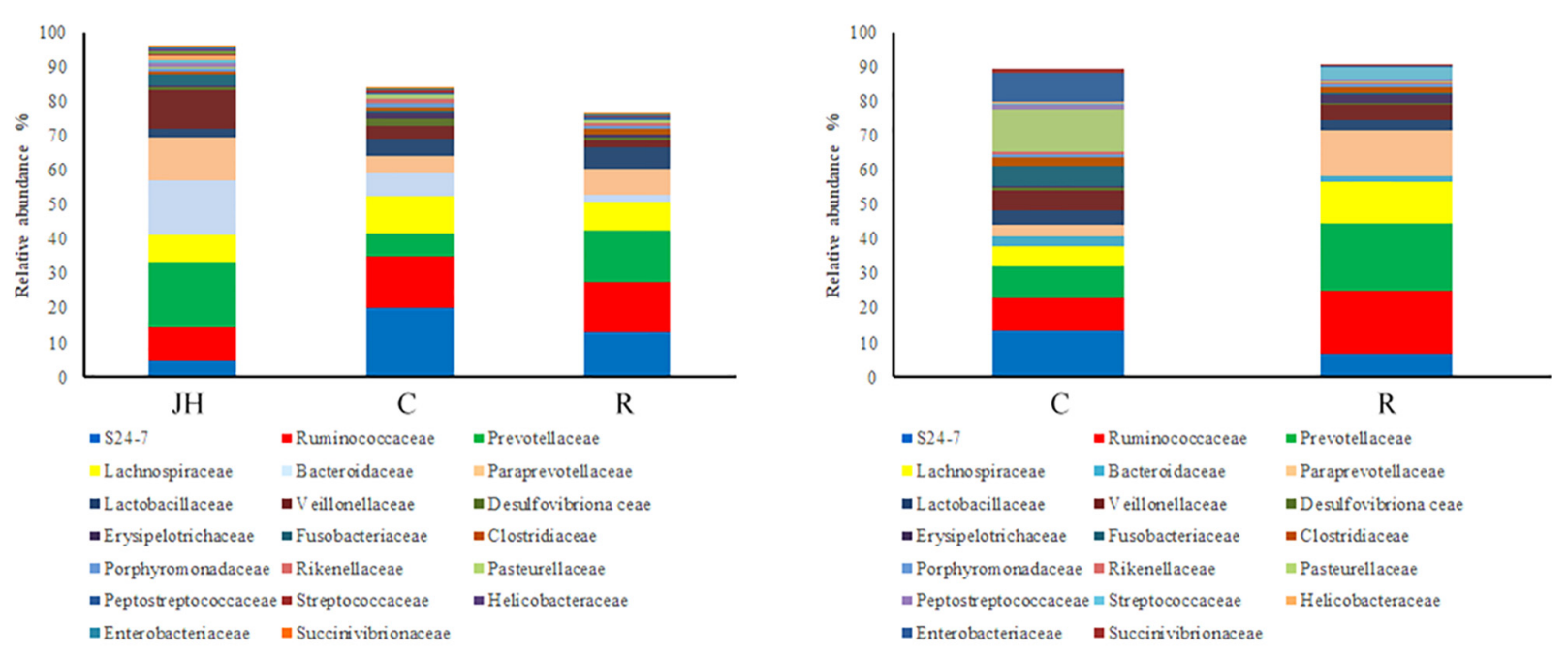

FIGURE 2 | 16 S rRNA gene analysis revealed the colonic bacterial community structure of piglets orally treated with or without exogenous fecal microflora (relative abundance of microflora in the level of family.) JH, Jinhua pigs. C, Control piglets. R, Recipient piglets.
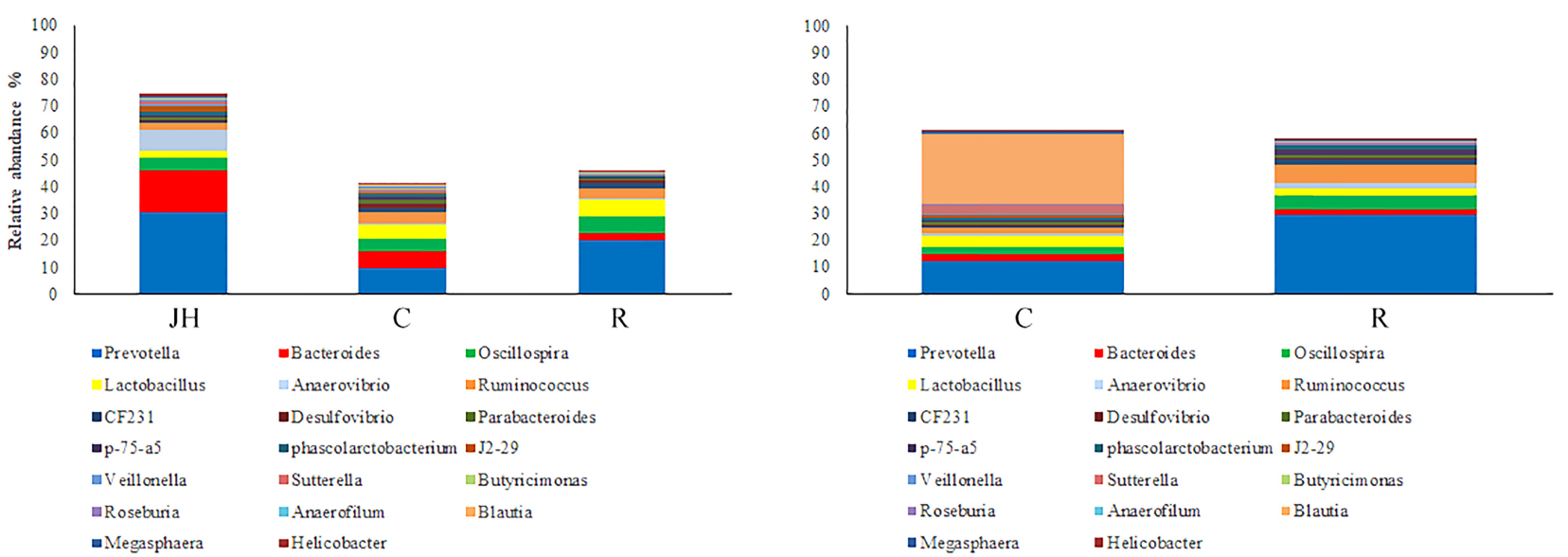

FIGURE 3 16S rRNA gene analysis revealed the colonic bacterial community structure of piglets orally treated with or without exogenous fecal microflora (relative abundance of microflora in the level of genus.) JH, Jinhua pigs. C, Control piglets. R, Recipient piglets.

piglets. The results showed, compared with control piglets, Firmicutes of recipient piglets were increased $(P<0.05)$ and a decreasing trend of Bacteroidetes was found in recipient piglets at day $12(P>0.05)$. At day 27 , recipient piglets had higher Firmicutes $(P<0.05)$ than control piglets. Proteobacteria of control piglets were significantly higher than that of recipient piglets $(P<0.05)$.

Relative abundance of gut microbial flora composition in the level of the family is shown in Figure 2. Prevotellaceae and Paraprevotellaceae were significantly increased of recipient piglets both on days 12 and $27(P<0.05)$. Fusobacteriaceae, Clostridiaceae, Pasteuriaceae, Alcaligenaceae, Bacteroidaceae, and Veillonellaceae were lower than the control on day $27(P<0.05)$. Compared with control piglets, there was an increasing trend of Lactobacillaceae of recipient piglets both on days 12 and 27 $(P>0.05)$.
Relative abundance of gut microbial flora composition in the level of genus is shown in Figure 3. Taxonomic profiles of the microbial communities in the colon were analyzed from genera and the figures are shown in Figures 4, 5. Compared with control, Prevotella, Oscillospira, CF231 were increased, Bacteroides were decreased of recipient piglets both on days 12 and $27(P<0.05)$. Ruminococcus were increased while j2-29, Sutterella, and Escherichia were decreased of the recipient piglets at day 27 $(P<0.05)$.

\section{Weight Gain and the Incidence of Diarrhea}

Diarrhea and average daily weight gain of piglets are shown in Figure 6. At days 1-12, there were no significant differences of ADG between control and recipient piglets $(P>0.05)$. At 


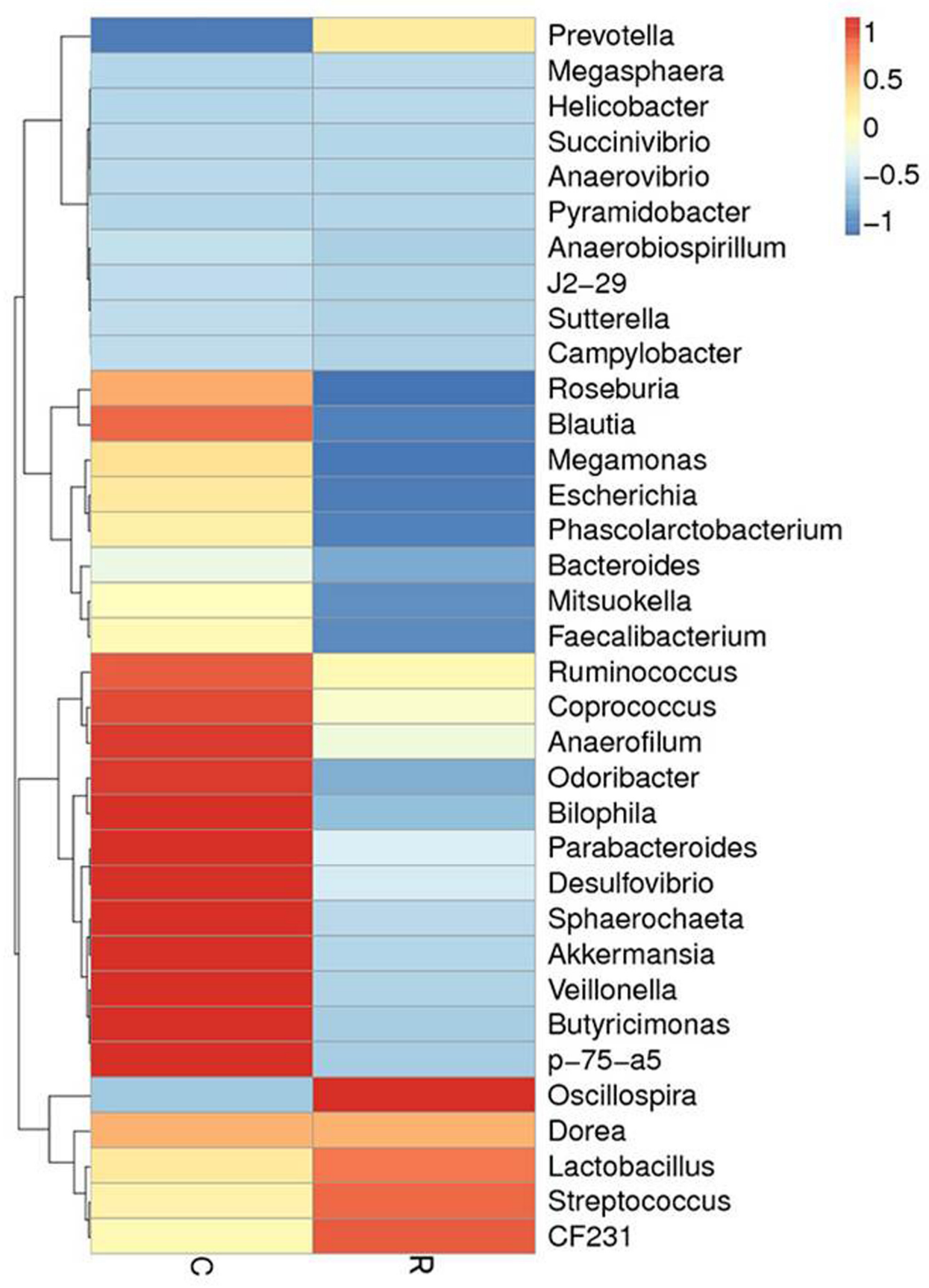

FIGURE 4 | The distribution of luminal bacteria in the colonic digesta at day 12. Taxonomic profiles of the microbial communities of the colon were analyzed from genera. Pigs with the highest and lowest bacterial levels are red and green, respectively. C, Control piglets. R, Recipient piglets.

days 1-27, ADG of the recipient piglets were higher than that of the control piglets $(P<0.05)$. Compared with control piglets, diarrhea incidence of recipient piglets was significantly decreased $(P<0.05)$.

\section{Intestinal Histology and Morphology}

Small intestine villi height and crypt depth of piglets are shown in Figure 7. At days 12 and 27, the crypt depth of the recipient piglets was significantly decreased compared with control piglets $(P<0.05)$, while there was no significant difference in villus height of the small intestine between recipient and control piglets $(P>0.05)$. The morphology of villi in jejunum observed by scanning electron microscope was shown in Figure 8. Compared with control piglets, jejunum villus morphology of recipient piglets was arranged appropriately, the villi were long and fingerlike, smooth and integrate. 


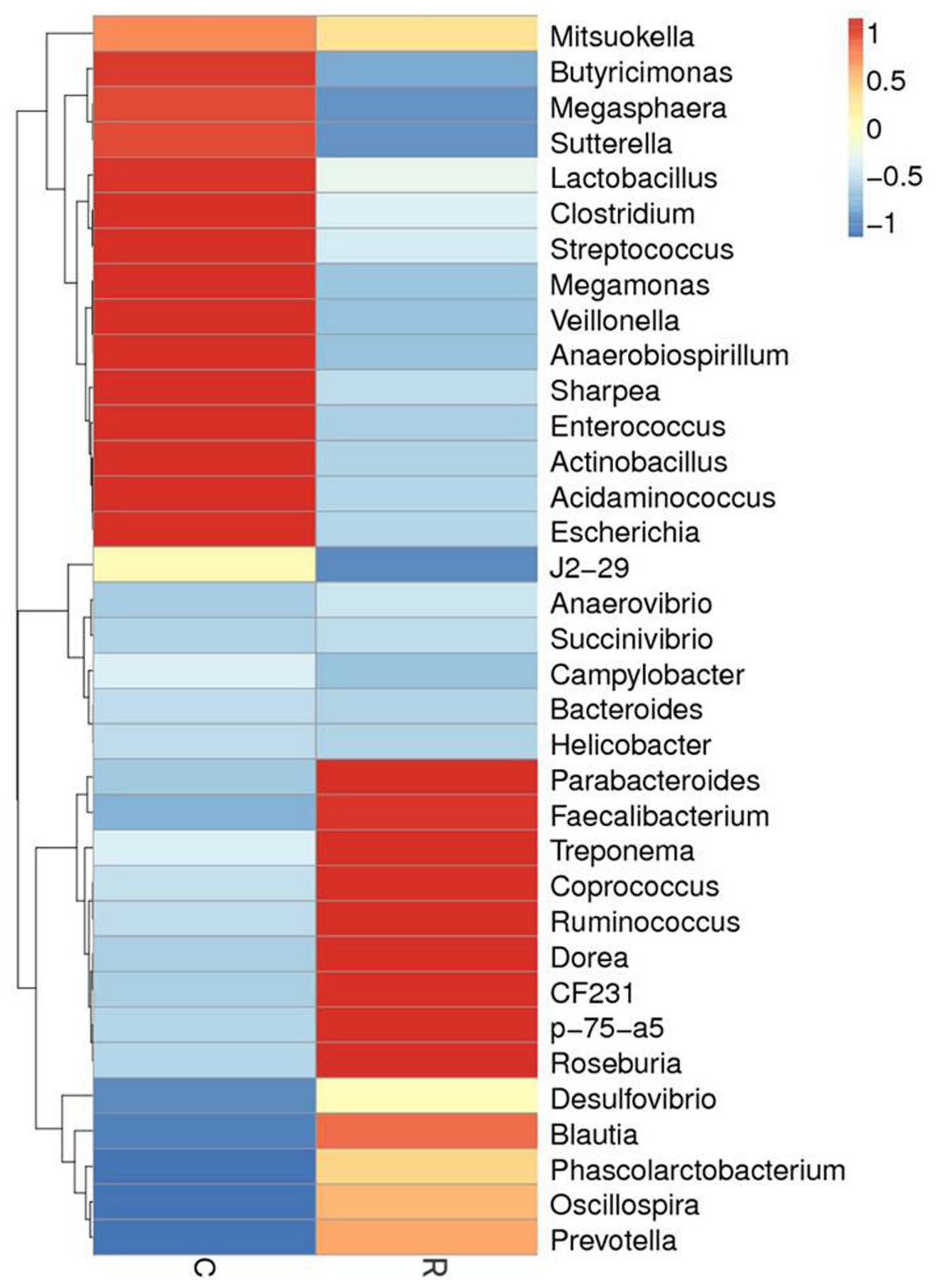

FIGURE 5 | The distribution of luminal bacteria in the colonic digesta at day 27. Taxonomic profiles of the microbial communities of the colon were analyzed from genera. Pigs with the highest and lowest bacterial levels are red and green, respectively. C, Control piglets. R, Recipient piglets.

\section{Relative Protein Expressions of Tight Junction Proteins in Intestine}

Relative protein expression of ZO-1 and Occludin in ileum and colon on days 12 and 27 is shown in Figure 9. Relative protein expression of ZO- 1 and Occludin in ileum and colon of recipient piglets on days 12 and 27 were both higher than that of the control $(P<0.05)$.

\section{Number of Goblet Cells in Intestine}

PAS staining of goblet cells is shown in Figure 10. Goblet cells distribution area in ileum and colon were broad and a large number of red secretory granules were observed both on days 12 and 27 of recipient piglets. The number of goblet cells in the ileum and colon was also shown in Figure 10. Compared with control piglets, the number of goblet cells in the ileum and colon of the 

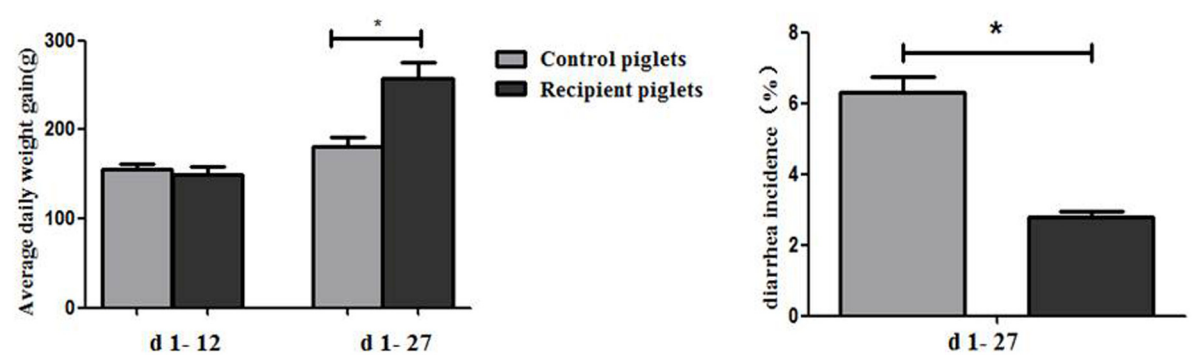

FIGURE 6 | Weight gain and the incidence of diarrhea in piglets orally treated with or without exogenous fecal microflora. Data are expressed as the mean \pm SEM. $* P<0.05$.
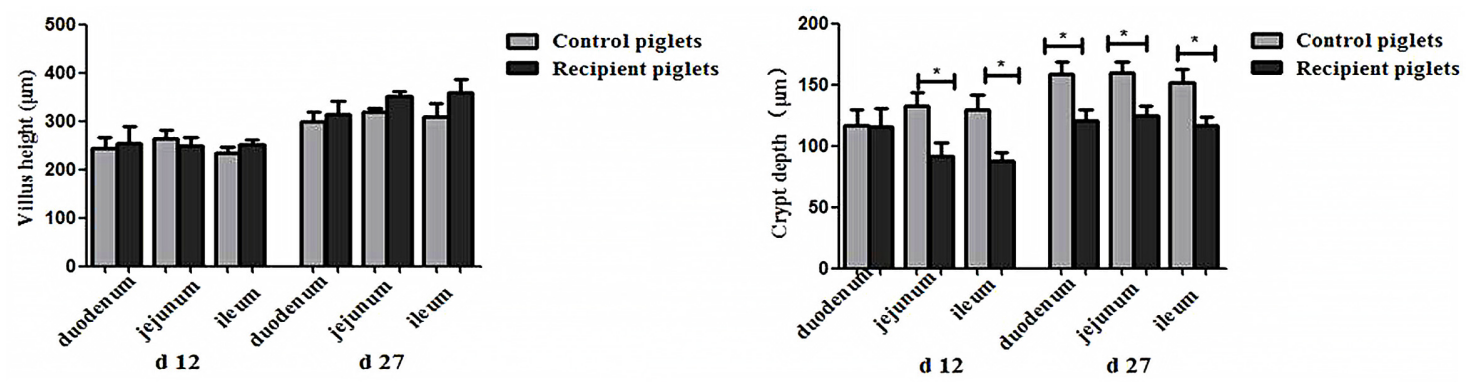

FIGURE 7 | Duodenal, jejunal and ileal morphology of piglets orally treated with or without exogenous fecal microflora. Data are expressed as the mean \pm SEM. $* P<0.05$.

recipient piglets was significantly increased both on days 12 and $27(P<0.05)$.

\section{Relative mRNA and Protein Expressions of MUC2 in Intestine}

The relative expression of mRNA and the protein of MUC2 are shown in Figure 11. At day 12, mRNA and protein expressions of MUC2 in the ileum and colon of the recipient piglets were both increased $(P<0.05)$. At day 27, mRNA and protein expressions of MUC2 in the colon of the recipient piglets were also increased $(P<0.05)$, though there was no significant change of it in the ileum $(P>0.05)$.

\section{Relative Protein Expressions of $\beta$-Defensin 2 in Intestine}

Relative protein expression of $\beta$-defensin 2 in the ileum mucosa on days 12 and 27 is shown in Figure 12. The expressions of $\beta$-defensin 2 in ileum of recipient piglets were higher than that of the control at days 12 and $27(P<0.05)$. The expressions of $\beta$-defensin 2 in ileum of piglets on day 27 were higher than that at day 12 both in control and recipient piglets $(P<0.05)$.

\section{The Concentration of sIgA in Intestine}

The optical density of $\operatorname{sig} \mathrm{A}^{+}$cells in the intestinal mucosa is shown in Figure 13. There were positive staining both in ileum and colon of recipient piglets. At day 12, the optical density of $\mathrm{sIgA}^{+}$cells in the colon of the recipient piglets was increased $(P<0.05)$. There were no significant differences in the optical density of sIgA $\mathrm{A}^{+}$cells in the ileum $(P>0.05)$. At day 27 , the optical density of $\operatorname{sig} \mathrm{A}^{+}$cells in the ileum and colon showed no significant change of the recipient compared to control piglets $(P>0.05)$.

\section{Relative mRNA Expression of TLR2 and TLR4 in Intestine}

The relative expression of TLR 2 and TLR4 in the colon is shown in Figure 14. Compared with control piglets, TLR2 and TLR4 in the colon of recipient piglets were significantly increased at day $12(P<0.05)$. TLR2 and TLR4 in the colon of recipient piglets at day 27 were not affected $(P>0.05)$.

\section{DISCUSSION}

The structure of intestinal microbial flora is not only affected by genetic factors, but is also susceptible to antibiotics, diseases, diets, environment as the starting early in life (Schroeder and Bäckhed, 2016). Infancy is a key period of colonization of gut microbial flora, during which microbiota structure is unstable and susceptible to the surrounding environment (Clemente et al., 2012). In this study, DLY newborn piglets were selected to receive fecal microbiota transplantation from healthy adult Jinhua pigs. The results showed that the relative abundance of Firmicutes and Proteobacteria in the colon of recipient piglets was increased, moreover, Firmicutes and Bacteroidetes were the two most abundant phyla of these piglets, and this result was similar to the previous study that Firmicutes and Bacteroidetes had an absolute 


\section{d 12}
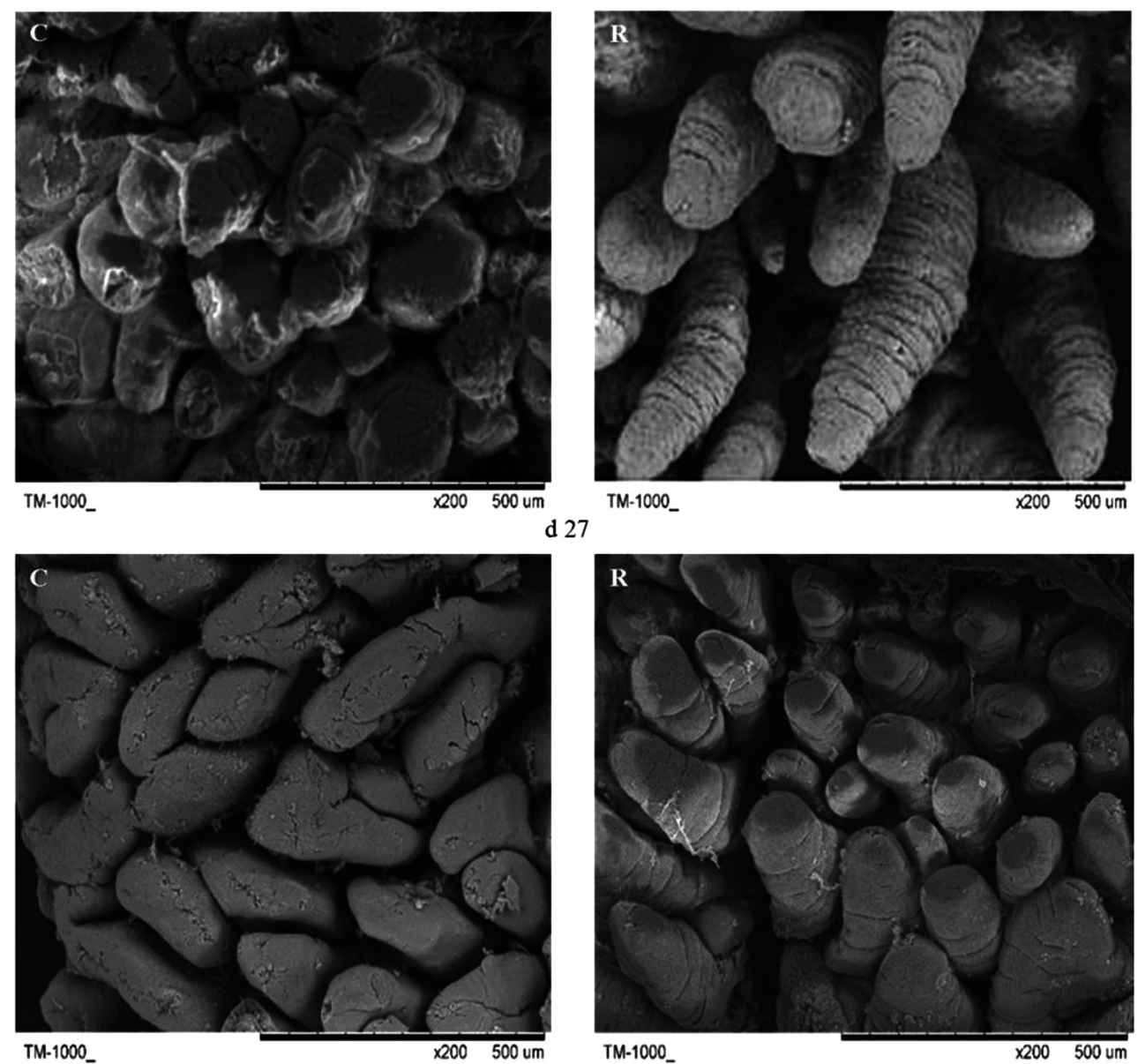

FIGURE 8 | Scanning electron micrograph of jejunal mucosal surface of piglets orally treated with or without exogenous fecal microflora $(200 \times$, bar = $500 \mu \mathrm{m})$. C, Control piglets. R, Recipient piglets.

advantage in mouse gut (Kulecka et al., 2016). In this study, the ratio of Firmicutes to Bacteroidetes was increased in recipient piglets, and the relative abundance of Firmicutes, Oscillospira, Prevotella was also enhanced. Firmicutes can maintain intestinal health by producing short-chain fatty acids, inhibit inflammation and provide energy for intestinal epithelial cells (Gophna et al., 2017). Firmicutes is also closely related to animal energy metabolism, and it is conducive to animal energy absorption of food under the condition that the proportion of Firmicutes is more than Bacteroides (Turnbaugh et al., 2006). Oscillospira can use host glycans as a source of energy, Oscillospira is also probably associated with the production of the short-chain fatty acid butyrate (Konikoff and Gophna, 2016). Prevotella is associated with digestion of carbohydrates (Wu et al., 2011). Veillonellaceae is associated with dietary intervention and pro-inflammatory (an increased abundance of Veillonellaceae was found in IBD, IBS, and cirrhosis patients) (Gevers et al., 2014; Haberman et al., 2014; Shukla et al., 2015; Bonder et al., 2016).

This study also showed that Escherichia of recipient piglets was decreased. Escherichia coli are a typically pathogenic species that infects intestine, and causes diarrhea and other serious gastrointestinal symptoms, and includes types such as enterotoxigenic and enteropathic E. coli (Camerlink et al., 2010). The above results suggested that intervarietal fecal microbiota transplantation increased the proportion of bacteria that benefit the host, and decreased harmful bacteria in the intestine of recipient piglets. Moreover, homology between the intestinal microbial flora of recipient piglets and donor pigs were closer after FMT, though a portion of bacteria in recipient piglets did not change with the corresponding bacteria in the donor. Similar to the structure of microbiota composition in donor pigs, the relative abundance of Firmicutes, Prevotellaceae, Paraprevotellaceae, Prevotella of recipient was increased. For these bacteria, receptor piglets showed a donor-like succession, which is consistent with the previous reports (Duca et al., 2014). The results also showed that Bacteroidaceae, Veillonellaceae, and Bacteroides of the recipient piglets were lower than the control, although it had a higher proportion in Jinhua pigs. Such shift phenomenon has also been reported in other studies (Pang et al., 2007). It might be due to the complex interaction 


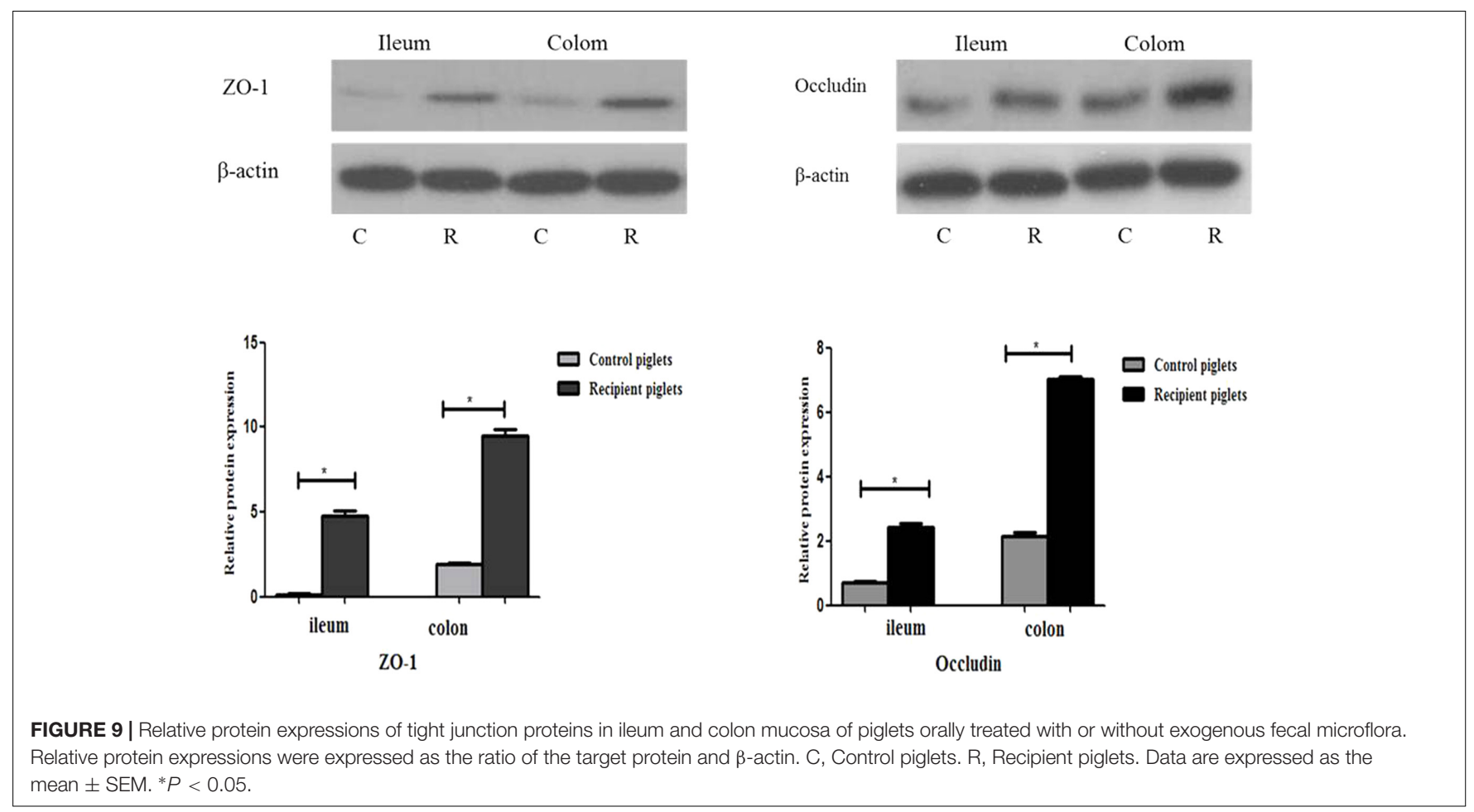

between microbial flora and colonization. Up to now, there were few studies about intervarietal fecal microbiota transplantation induced changes in the structure of intestinal microbial flora in pigs.

As the gut of a newborn pig is not fully developed, intestinal microbial floras are in an unstable state. At the same time, the development of its immune system is not mature enough, thus piglets are susceptible to a variety of pathogens (Xu et al., 1992) Piglets are weak in resistance, diarrhea would happen under this condition. Diarrhea would lead to the decrease of survival rate and growth retardation of piglets. The proportion of Bifidobacterium would decrease, Enterobacterium, Bacteroides and Clostridium would increase when diarrhea happens (Vondruskova et al., 2010). Clinical practice trials showed that the patients with toxic megacolon caused by C. difficile infection were treated by FMT successfully, and the frequency of diarrhea was decreased rapidly (Gweon et al., 2015). The diarrhea incidence of recipient piglets was decreased significantly in this study. As mentioned above, Escherichia are connect with many diseases including diarrhea (Camerlink et al., 2010). It indicated that the decrease of diarrhea incidence might ascribe to the reduction of colonic Escherichia. Intestinal ecosystem of piglets is closely related to its growth characteristics (Ramayo-Caldas et al., 2016). The microbial structures of the heavier body weight piglets are different from the lighter ones (Han et al., 2016). The increase of bacteria mentioned above, which associate with nutrient absorption and metabolism might also lead to the weight gain of the recipient. Consistently, the piglets inoculated with fecal microbiota suspension performed better than the control piglets in this study, and the differences in the intestinal microbial composition between recipient and donor led to the differences in their weight gain. Moreover, the decrease of diarrhea incidence might also contribute to weight gains of recipient piglets.

The development of intestine in newborn piglets is rapid, which include tissue growth, morphology changes and functions maturity. The villi capillaries of conventional mice were better developed compared to germfree mice, which suggested that the gut microbiota contribution to the development of the intestinal villi (Hooper, 2004). The growth rate of crypts affects growth and atrophy of the intestinal villi, the reduction of crypt depth indicate an increase of epithelial cell maturation rate and absorptive capacity. So the decrease of crypt depth in recipient piglets in this study indicated the enhanced ability of absorption and digestion in the small intestinal epithelium. As shown under microscope, jejunal villi of recipient piglets were smooth with luminal integrity, while the control group showed broken luminal integrity. The scanning electron microscopes result indicated that that intestinal villus morphology was improved by fecal microbiota suspension.

The integrity of the intestinal barrier structure is the basis for maintaining normal intestinal function. Tight junction is an important part of intestinal mucosa mechanical barrier function, which prevents bacteria and other antigens from spreading over the epithelial cells (Ulluwishewa et al., 2011). Tight junction proteins are often used as an indicator for the function of the barrier and the permeability in the intestine, including: occluding, ZO-1, and cladding. Improvements of intestinal barrier integrity were associated with tight junction proteins expression levels (Ulluwishewa et al., 2011). Microbiota can lead to the increase of tight junction proteins at cell boundaries, and 


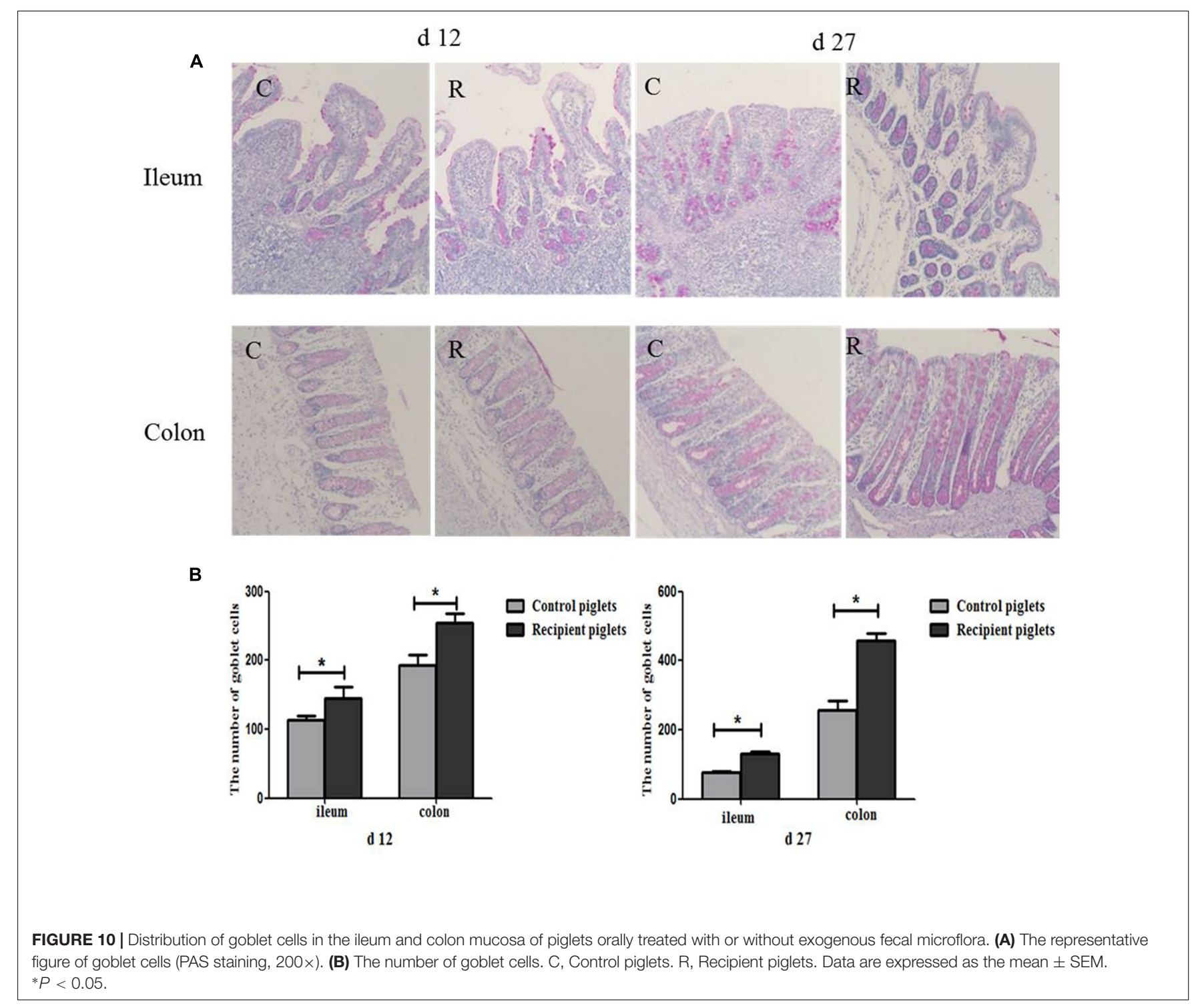

prevent or reverse the harmful effect of pathogens in the intestine in some cases (Ulluwishewa et al., 2011). Studies have shown that probiotics can regulate tight junctions through bacterial metabolites (Hsieh et al., 2015). The expressions of tight junction proteins in the intestine of recipients were increased in this study.

As the first line of defense against intestinal microbial invasion host, goblet cells play a key role in the identification of intestinal microorganism (Shen, 2009). Intestinal microbes can directly regulate the goblet cell function by delivering local biologically active factors. And the functions of goblet cells can also be changed by host-derived bioactive factors which are produced by active epithelial or underlying lamina propria cells after contacting with intestinal bacteria (Deplancke and Gaskins, 2001). Intestinal goblet cells in the sterile-fed mice were fewer in number and smaller in volume as compared with that of the conventionally fed mice, which demonstrated that microbe regulates the number of goblet cells (Deplancke and Gaskins, 2001). In the present study, the number of goblet cells in the colon was higher than in jejunum both on days 12 and 27 which was consistent with the Karam (1999) report. From duodenum to the ileum, and jejunum, the ratio of goblet cells in all epithelial cells occupied 4,6 , and $12 \%$. In the distal colon, the goblet cells proportion increased to $16 \%$. This coincides with a gradual increase in the number of microbes from the proximal intestine to the colon. Goblet cells mainly secrete making that cover intestinal epithelial surface, and play the role of mechanical protective barrier (Linden et al., 2008). Mucins lubricate intestine and protect it from the damage of potential pathogens, mutagens, as well as mechanical and chemical damage (Neutra and Forstner, 1987). The predominant gel-forming mucin in the intestine is MUC2, which could be expressed by goblet cells throughout intestine (Johansson and Hansson, 2016). Without microbiota in the intestinal tract, the thickness of the mucous layer will become thinner, and bacteria can contact with the epithelium directly, translocate and trigger the submucosal immune system to cause an immune response (van Vliet et al., 2010; Johansson 
d 12
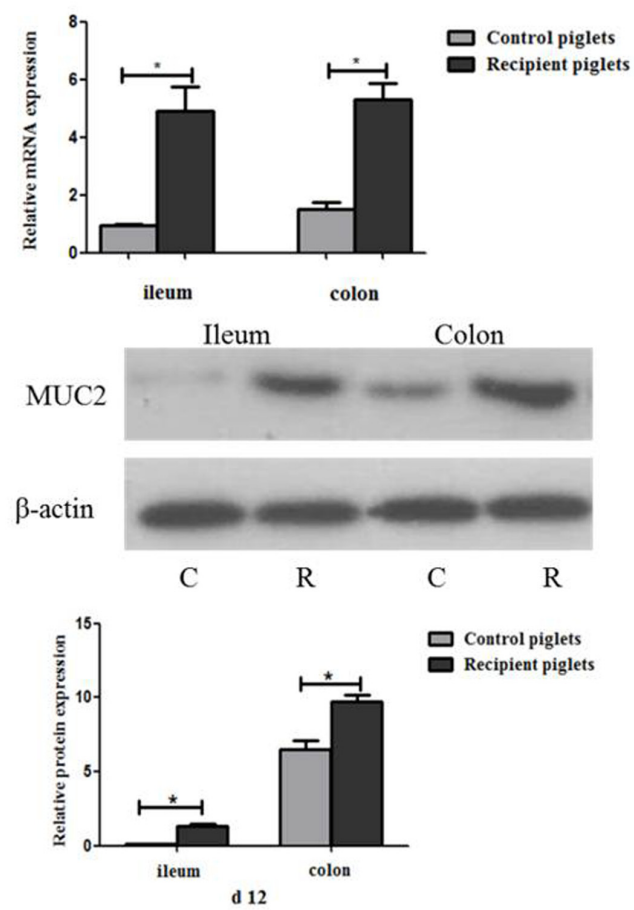

d 27

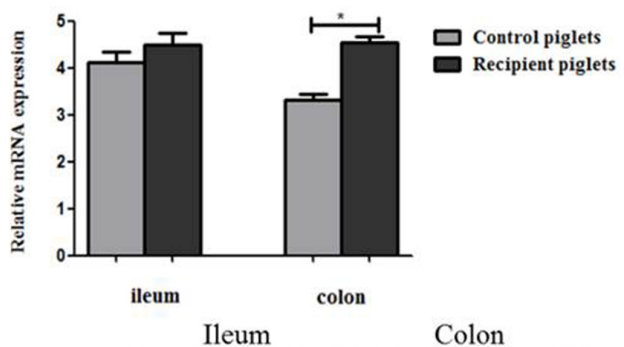

MUC2

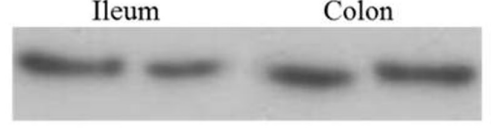

$\beta$-actin

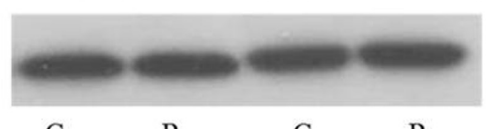

C

C R

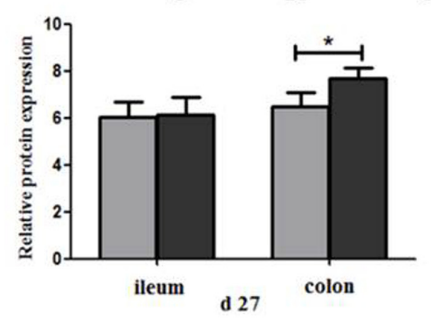

FIGURE 11 | Relative mRNA and protein expressions of MUC2 in ileum and colon mucosa of piglets orally treated with or without exogenous fecal microflora. Relative protein expressions were expressed as the ratio of the target protein and $\beta$-actin. $C$, Control piglets. $R$, Recipient piglets. Data are expressed as the mean \pm SEM. ${ }^{*} P<0.05$.

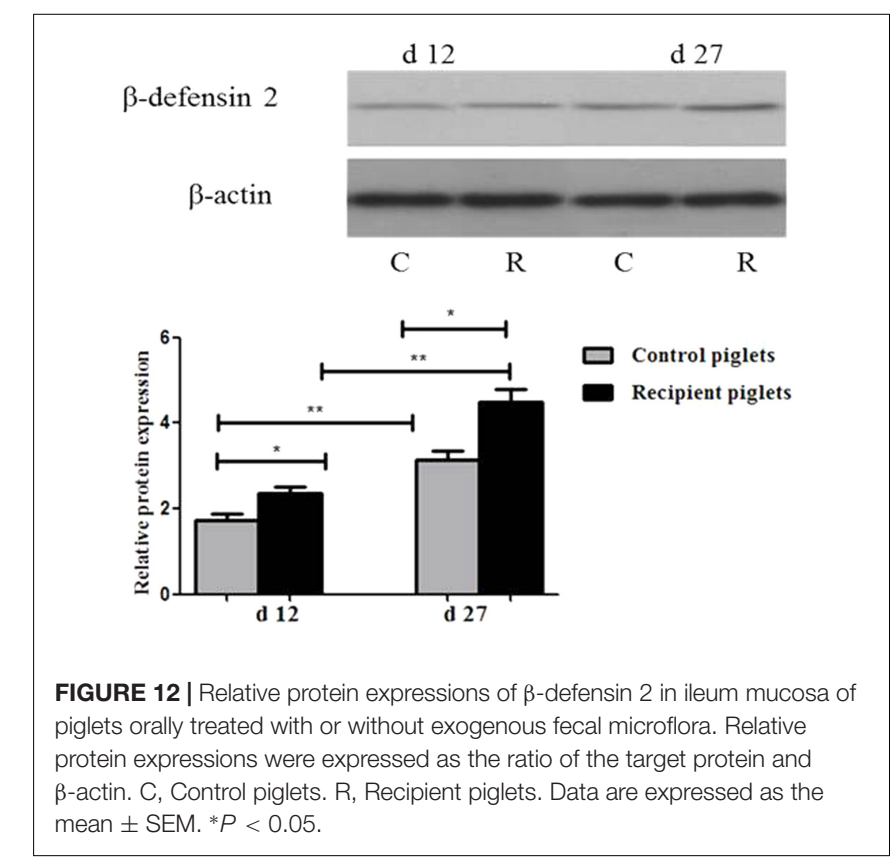

and Hansson, 2016). Different bacteria species in the colon of mouse also led to the differences in mucin production capacity (Caballero et al., 2015). So in this study, the different structure of intestinal microbial flora may also cause the different expressions of MUC2 in the intestine. The intestinal microbiota induced mucin production and antibiotic administration resulted in thinning of the mucus barrier, thereby increasing susceptibility to bacterial invasion (Wlodarska et al., 2011). The present study showed that mRNA and protein expressions of MUC2 were up-regulated in recipient piglets. The increase of MUC2 might be attributed to the increase of the number of goblet cells. The results indicated that the exogenous fecal microbiota suspension had a beneficial effect on the development of intestinal mucous barrier in recipient piglets. So in this study, intestinal morphology and intestinal barrier function was improved via intervarietal fecal microbiota transplantation.

There are a wide variety of antimicrobial peptides, which aid congenital barrier resist microbial infection. As the first line of innate immunity in mammals, antibacterial peptides are a class of small molecules that are widely found in animals. The expression of $\beta$-defensin 2 gene is inducible and induced by intestinal microbes in the intestine of pigs (Veldhuizen et al., 2006). The immune system of newborn piglets is imperfect, antimicrobial peptides are the key effector molecules of innate immunity at this stage. The expression of antimicrobial peptide gene in the intestine of mice increased gradually with age after birth (Ménard et al., 2008). $\beta$-defensin 2 increased gradually with age was also found in this study, the expressions of $\beta$-defensin 2 in ileum of recipient piglets on day 27 were higher than that of piglets on day 12. Moreover, the expressions of $\beta$-defensin 2 in recipient piglets were enhanced. The expressions 

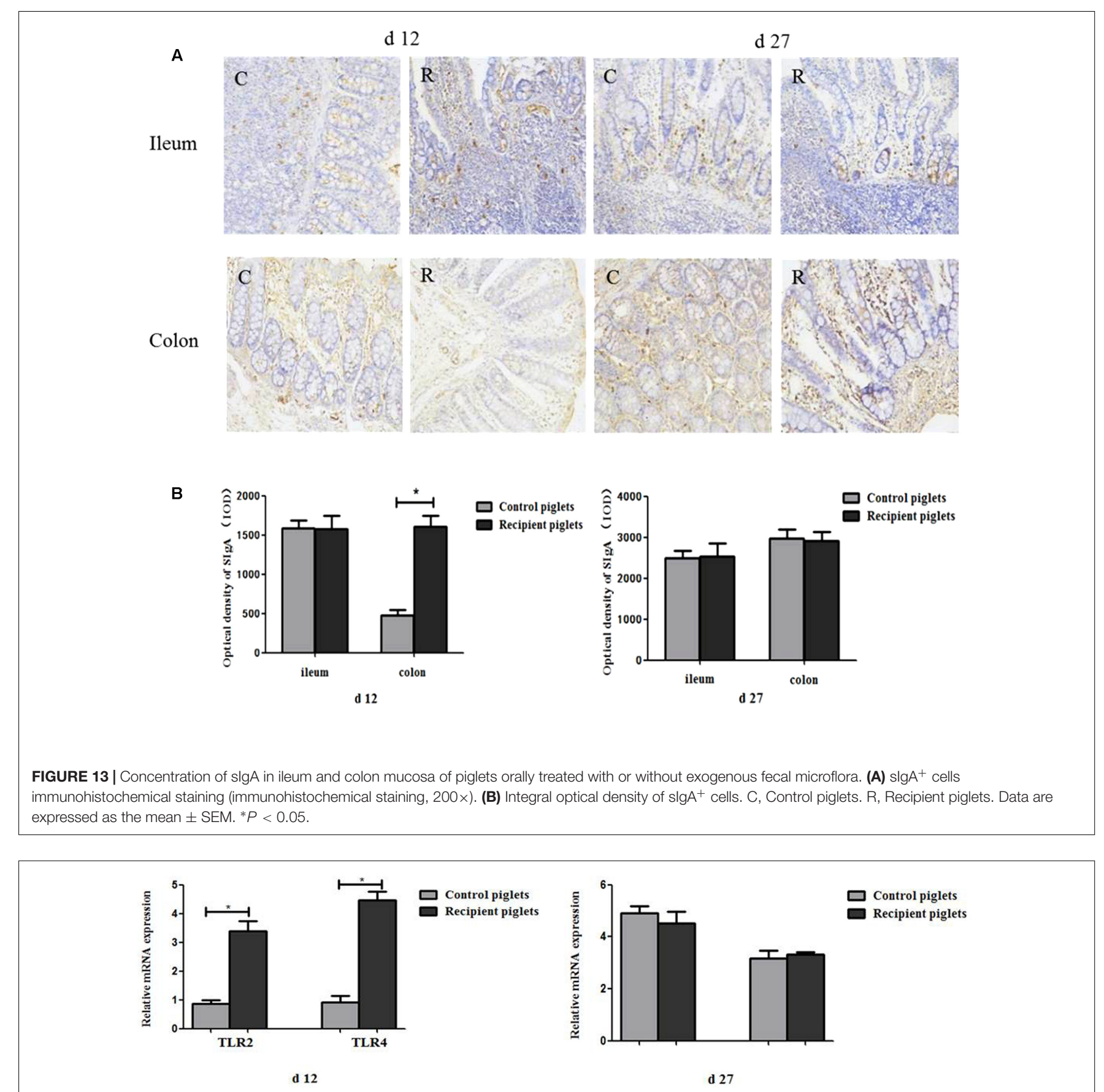

FIGURE 14 | Relative mRNA expressions of TLR2 and TLR4 in colon mucosa of piglets orally treated with or without exogenous fecal microflora. Data are expressed as the mean \pm SEM. $* P<0.05$.

of defensin vary in breeds of piglets. It has been reported that the expression level of defensin gene in the intestine of Jinhua pig was higher than that in Landrace pig (An et al., 2011). And they consider that $\beta$-defensin play the key role during each stage of piglets growth and development that the expression of $\beta$-defensin is different in different breeds might contribute to the various disease resistance of pigs. We found that the expressions of $\beta$-defensin 2 in recipient piglets were higher than that of the control in this study. It indicated that intervarietal fecal microbiota promoted expressions of intestinal antimicrobial peptides in DLY recipient piglets. Increased expressions of antimicrobial peptide contributed to the improvement of the resistance of recipients to diseases.

As predominant immunoglobulin isotype on most mucosal surfaces (Otten and van Egmond, 2004; Snoeck et al., 2006), secretory immunoglobulin A ( $\operatorname{IgA}$ ) can protect intestinal tract 
from dietary and microbial antigens (Bakker-Zierikzee et al., 2006). Except for the inhibition of adherence and invasion of potentially harmful antigens into mucosa, sIgA also can neutralize toxins and virulence factors from microbial pathogens (Brandtzaeg, 2003). The innate inflammatory response of neonates is not mature enough to prevent pathogen invasion (Walker, 2010). The relationship between microbes and $\operatorname{sIgA}$ is mutual adjustment. SIgA in the intestinal mucosa of mice that the intestinal microbial flora imbalanced caused by antibiotic were increased after receiving fecal microbiota suspension ( $\mathrm{Li}$ et al., 2015). The balance of original intestinal microbiota in recipient piglets would be disrupted after fecal suspension was treated and the optical density of $\operatorname{sig} \mathrm{A}^{+}$cells in the colon was also increased in recipient piglets consistently. More and more bacterial colonization facilitates the maturation of mucosal immune system and is associated with the production of the large amount of sIgA, which stabilizes the microbiota-host interaction (Pabst et al., 2016). Exogenous fecal microbiota suspension stimulated proliferation of $\operatorname{sga} \mathrm{A}^{+}$cells and the development of the intestinal immune system of piglets.

The composition of intestinal microbiota and function of the immune system is closely related (Round and Mazmanian, 2009). As a sensor for microbial infection, TLRs are critical for initiation of inflammation and immune defense responses (Rakoff-Nahoum et al., 2004). TLR recognized bacterial ligands that are not only unique to pathogens, but shared by all bacteria, and also produced by symbiotic microorganisms (Chen et al., 2010). Previous studies have shown that intestinal microbiota can activate TLR2/TLR4 on the luminal surface of epithelial cells and may subsequently improve intestinal barrier function through promoting the assembly of intestinal tight junctionassociated molecules as well as regulating the proliferation and apoptosis of epithelial cells (Rakoff-Nahoum et al., 2004; Fukata et al., 2006; Cario et al., 2007). Stimulated by exogenous fecal bacteria, TLR2 and TLR4 of recipient piglets on day 12 were increased. As mentioned above, exogenous microbial flora might break the original balance of microbiota, therefore, TLRs in the intestine of piglets were significantly increased by the stimulation of exogenous fecal microbiota. However, there were no significant differences in the expressions of TLRs on day 27 , which might indicate that intestinal microbiota of recipient

\section{REFERENCES}

An, S., Han, F. F., Gao, Y. H., Liu, Y., and Wang, Y. Z. (2011). Gene expression profile of $\beta$-defensins in intestinal tract of jinhua and landrace pigs. Chin. J. Anim. Nutr. 23, 1762-1768.

Bakker-Zierikzee, A. M., Tol, E. A. F., Kroes, H., Alles, M. S., Kok, F. J., and Bindels, J. G. (2006). Faecal SIgA secretion in infants fed on pre-or probiotic infant formula. Pediatr. Allergy Immunol. 17, 134-140. doi: 10.1111/j.1399-3038.2005. 00370.x

Ben-Neriah, Y., and Schmidt-Supprian, M. (2007). Epithelial NF-кB maintains host gut microflora homeostasis. Nat. Immunol. 8, 479-481. doi: 10.1038/ni0507-479

Bojanova, D. P., and Bordenstein, S. R. (2016). Fecal transplants: What is being transferred? PLOS Biol. 14:e1002503. doi: 10.1371/journal.pbio. 1002503

Bonder, M. J., Tigchelaar, E. F., Cai, X., Trynka, G., Cenit, M. C., Hrdlickova, B., et al. (2016). The influence of a short-term gluten-free diet on the human gut microbiome. Genome Med. 8:45. doi: 10.1186/s13073-016-0295-y piglets was reestablished and the new homeostasis stablished. The activation of TLRs by commensal bacteria is essential for maintaining homeostasis in the colon (Ben-Neriah and SchmidtSupprian, 2007). Sensing of commensal bacteria by TLRs in epithelial does not elicit an inflammatory cascade but is required for the maintenance of the epithelial barrier and contributes to TLR-dependent intestinal homeostasis observed in vivo (RakoffNahoum et al., 2004; Cario and Podolsky, 2005). Moreover, the induced TLR receptors in intestinal epithelium also can stimulate an innate immune response and activate the PP to secrete antimicrobial peptides (Wang et al., 2016), and lead to the induction of MUC2 (Ikeda et al., 2007). The study indicated that the expression of TLRs were up-regulated under the condition that intestinal microbial flora was imbalanced and didn't change when the structure of intestinal microbiota restored to steady state.

In summary, some characteristics of donor pigs could be transferred to recipient neonatal piglets by fecal microbiota suspension in this study. Exogenous fecal microbiota suspension changed the structure of intestinal microbial flora as well as contributed to the improvement of intestinal morphology, the development of the intestinal mucosal barrier and innate immunity in recipient piglets. Therefore, the recipients' resistance to disease was enhanced, diarrhea was reduced and weight gain was raised. Fecal microbiota transplantation might be an efficient way to improve young animals' resistance to disease by changing the structure of intestinal microbial flora.

\section{AUTHOR CONTRIBUTIONS}

$\mathrm{XH}$ conceived and designed the experiments. LH and SG performed the experiments, analyzed the data and drafted the manuscript. YL, SC, XF, and XY performed the experiments and analyzed the data.

\section{ACKNOWLEDGMENT}

This work was supported by the Natural Science Foundation of Zhejiang Province, China (LZ18C170001).

Brandtzaeg, P. (2003). Role of secretory antibodies in the defence against infections. Int. J. Med. Microbiol. 293, 3-15. doi: 10.1078/1438-4221-00241

Caballero, S., Carter, R., Ke, X., Sušac, B., Leiner, I. M., Kim, G. J., et al. (2015). Distinct but spatially overlapping intestinal niches for vancomycin-resistant Enterococcus faecium and carbapenem-resistant Klebsiella pneumoniae. PLOS Pathog. 11:e1005132. doi: 10.1371/journal.ppat.1005132

Camerlink, I., Ellinger, L., Bakker, E. J., and Lantinga, E. A. (2010). Homeopathy as replacement to antibiotics in the case of Escherichia coli diarrhoea in neonatal piglets. Homeopathy 99, 57-62. doi: 10.1016/j.homp.2009.10.003

Cario, E., Gerken, G., and Podolsky, D. K. (2007). Toll-like receptor 2 controls mucosal inflammation by regulating epithelial barrier function. Gastroenterology 132, 1359-1374. doi: 10.1053/j.gastro.2007.02.056

Cario, E., and Podolsky, D. K. (2005). Intestinal epithelial TOLLerance versus in TOLLerance of commensals. Mol. Immunol. 42, 887-893. doi: 10.1016/j. molimm.2004.12.002

Chen, L. W., Chang, W. J., Chen, P. H., and Hsu, C. M. (2010). Commensal microflora induce host defense and decrease bacterial translocation in burn 
mice through toll-like receptor 4. J. Biomed. Sci. 17:48. doi: 10.1186/1423-0127$17-48$

Clemente, J. C., Ursell, L. K., Parfrey, L. W., and Knight, R. (2012). The impact of the gut microbiota on human health: an integrative view. Cell 148, 1258-1270. doi: 10.1016/j.cell.2012.01.035

Deplancke, B., and Gaskins, H. R. (2001). Microbial modulation of innate defense: goblet cells and the intestinal mucus layer. Am. J. Clin. Nutr. 73, 1131S-1141S.

Duca, F. A., Sakar, Y., Lepage, P., Devime, F., Langelier, B., Doré, J., et al. (2014). Replication of obesity and associated signaling pathways through transfer of microbiota from obese-prone rat. Diabetes 63, 1624-1636. doi: 10.2337/db131526

Fukata, M., Chen, A., Klepper, A., Krishnareddy, S., Vamadevan, A. S., Thomas, L. S., et al. (2006). Cox-2 is regulated by Toll-like receptor-4 (TLR4) signaling: role in proliferation and apoptosis in the intestine. Gastroenterology 131, 862-877. doi: 10.1053/j.gastro.2006.06.017

Gao, Y., Han, F., Huang, X., Rong, Y., Yi, H., and Wang, Y. (2013). Changes in gut microbial populations, intestinal morphology, expression of tight junction proteins, and cytokine production between two pig breeds after challenge with K88: a comparative study. J. Anim. Sci. 91, 5614-5625. doi: 10.2527/jas.20136528

Gevers, D., Kugathasan, S., Denson, L. A., Vázquez-Baeza, Y., Van Treuren, W., Ren, B., et al. (2014). The treatment-naive microbiome in new-onset Crohn's disease. Cell Host Microbe 15, 382-392. doi: 10.1016/j.chom.2014. 02.005

Gophna, U., Konikoff, T., and Nielsen, H. B. (2017). Oscillospira and related bacteria - from metagenomic species to metabolic features. Environ. Microbiol. 19, 835-841. doi: 10.1111/1462-2920.13658

Gweon, T. G., Lee, K. J., Kang, D., Park, S. S., Kim, K. H., Seong, H., et al. (2015). A case of toxic megacolon caused by Clostridium difficile infection and treated with fecal microbiota transplantation. Gut Liver 9, 247-250. doi: $10.5009 /$ gnl14152

Haberman, Y., Tickle, T. L., Dexheimer, P. J., Kim, M. O., Tang, D., Karns, R., et al. (2014). Pediatric Crohn disease patients exhibit specific ileal transcriptome and microbiome signature. J. Clin. Invest. 124, 3617-3633. doi: 10.1172/JCI75436

Han, G. G., Lee, J. Y., Jin, G. D., Park, J., Choi, Y. H., Chae, B. J., et al. (2016). Evaluating the association between body weight and the intestinal microbiota of weaned piglets via $16 \mathrm{~S}$ rRNA sequencing. Appl. Microbiol. Biotechnol. 101, 5903-5911. doi: 10.1007/s00253-017-8304-7

Han, X. Y., Ma, Y. F., Lv, M. Y., Wu, Z. P., and Qian, L. C. (2014). Chitosanzinc chelate improves intestinal structure and mucosal function and decreases apoptosis in ileal mucosal epithelial cells in weaned pigs. Br. J. Nutr. 111, 1405-1411. doi: 10.1017/S0007114513004042

Ho, J. T., Chan, G. C., and Li, J. C. (2015). Systemic effects of gut microbiota and its relationship with disease and modulation. BMC Immunol. 16:21. doi: 10.1186/s12865-015-0083-2

Hooper, L. V. (2004). Bacterial contributions to mammalian gut development. Trends Microbiol. 12, 129-134. doi: 10.1016/j.tim.2004.01.001

Hsieh, C.-Y., Osaka, T., Moriyama, E., Date, Y., Kikuchi, J., and Tsuneda, S. (2015). Strengthening of the intestinal epithelial tight junction by Bifidobacterium bifidum. Physiol. Rep. 3:e12327. doi: 10.14814/phy2.12327

Ikeda, H., Sasaki, M., Ishikawa, A., Sato, Y., Harada, K., Zen, Y., et al. (2007). Interaction of Toll-like receptors with bacterial components induces expression of CDX2 and MUC2 in rat biliary epithelium in vivo and in culture. Lab. Invest. 87, 559-571. doi: 10.1038/labinvest.3700556

Johansson, M. E., and Hansson, G. C. (2016). Immunological aspects of intestinal mucus and mucins. Nat. Rev. Immunol. 16, 639-649. doi: 10.1038/nri.2016.88

Karam, S. M. (1999). Lineage commitment and maturation of epithelial cells in the gut. Front. Biosci. 4, D286-D298.

Koboziev, I., Webb, C. R., Furr, K. L., and Grisham, M. B. (2014). Role of the enteric microbiota in intestinal homeostasis and inflammation. Free Radic. Biol. Med. 68, 122-133. doi: 10.1016/j.freeradbiomed.2013.11.008

Konikoff, T., and Gophna, U. (2016). Oscillospira: a central, enigmatic component of the human gut microbiota. Trends Microbiol. 24, 523-524. doi: 10.1016/j.tim. 2016.02.015

Kulecka, M., Paziewska, A., Zeber-Lubecka, N., Ambrozkiewicz, F., Kopczynski, M., Kuklinska, U., et al. (2016). Prolonged transfer of feces from the lean mice modulates gut microbiota in obese mice. Nutr. Metab. 13:57. doi: 10.1186/s12986-016-0116-8
Li, M., Liang, P., Li, Z., Wang, Y., Zhang, G., Gao, H., et al. (2015). Fecal microbiota transplantation and bacterial consortium transplantation have comparable effects on the re-establishment of mucosal barrier function in mice with intestinal dysbiosis. Front. Microbiol. 6:692. doi: 10.3389/fmicb.2015.00692

Linden, S. K., Sutton, P., Karlsson, N. G., Korolik, V., and McGuckin, M. A. (2008). Mucins in the mucosal barrier to infection. Mucosal Immunol. 1, 183-197. doi: $10.1038 / \mathrm{mi} .2008 .5$

Livak, K. J., and Schmittgen, T. D. (2001). Analysis of relative gene expression data using real-time quantitative PCR and $2^{-\Delta \Delta C_{\mathrm{T}}}$ Method. Methods 25, 402-408. doi: 10.1006/meth.2001.1262

Ménard, S., Förster, V., Lotz, M., Gütle, D., Duerr, C. U., Gallo, R. L., et al. (2008). Developmental switch of intestinal antimicrobial peptide expression. J. Exp. Med. 205, 183-193. doi: 10.1084/jem.20071022

Merrifield, C. A., Lewis, M., Claus, S. P., Beckonert, O. P., Dumas, M. E., Duncker, S., et al. (2011). A metabolic system-wide characterisation of the pig: a model for human physiology. Mol. BioSyst. 7, 2577-2588. doi: 10.1039/ clmb05023k

Moya, A., and Ferrer, M. (2016). Functional redundancy-induced stability of gut microbiota subjected to disturbance. Trends Microbiol. 24, 402-413. doi: 10.1016/j.tim.2016.02.002

Neutra, M. R., and Forstner, J. F. (1987). Gastrointestinal mucus: synthesis, secretion, and function. Physiol. Gastrointestinal Tract. 2, 975-1009.

Otten, M. A., and van Egmond, M. (2004). The Fc receptor for IgA (FcaRI, CD89). Immunol. Lett. 92, 23-31. doi: 10.1016/j.imlet.2003.11.018

Pabst, O., Cerovic, V., and Hornef, M. (2016). Secretory IgA in the coordination of establishment and maintenance of the microbiota. Trends Immunol. 37, 287-296. doi: 10.1016/j.it.2016.03.002

Pang, X., Hua, X., Yang, Q., Ding, D., Che, C., Cui, L., et al. (2007). Inter-species transplantation of gut microbiota from human to pigs. ISME J. 1, 156-162. doi: 10.1038 /ismej.2007.23

Puiman, P., and Stoll, B. (2008). Animal models to study neonatal nutrition in humans. Curr. Opin. Clin. Nutr. Metab. Care 11, 601-606. doi: 10.1097/MCO. 0b013e32830b5b15

Rakoff-Nahoum, S., Paglino, J., Eslami-Varzaneh, F., Edberg, S., and Medzhitov, R. (2004). Recognition of commensal microflora by toll-like receptors is required for intestinal homeostasis. Cell 118, 229-241. doi: 10.1016/j.cell.2004.07.002

Ramayo-Caldas, Y., Mach, N., Lepage, P., Levenez, F., Denis, C., Lemonnier, G., et al. (2016). Phylogenetic network analysis applied to pig gut microbiota identifies an ecosystem structure linked with growth traits. ISME J. 10, 2973-2977. doi: 10.1038/ismej.2016.77

Round, J. L., and Mazmanian, S. K. (2009). The gut microbiome shapes intestinal immune responses during health and disease. Nat. Rev. Immunol. 9, 313-323. doi: $10.1038 /$ nri2515

Schroeder, B. O., and Bäckhed, F. (2016). Signals from the gut microbiota to distant organs in physiology and disease. Nat. Med. 22, 1079-1089. doi: 10.1038/nm. 4185

Shen, L. (2009). "Functional morphology of the gastrointestinal tract," in Molecular Mechanisms of Bacterial Infection via the Gut, ed. C. Sasakawa (Berlin: Springer), 1-35. doi: 10.1007/978-3-642-01846-6_1

Shukla, R., Ghoshal, U., Dhole, T. N., and Ghoshal, U. C. (2015). Fecal microbiota in patients with irritable bowel syndrome compared with healthy controls using real-time polymerase chain reaction: an evidence of dysbiosis. Dig. Dis. Sci. 60, 2953-2962. doi: 10.1007/s10620-015-3607-y

Snoeck, V., Peters, I. R., and Cox, E. (2006). The IgA system: a comparison of structure and function in different species. Vet. Res. 37, 455-467. doi: 10.1051/ vetres:2006010

Turnbaugh, P. J., Ley, R. E., Mahowald, M. A., Magrini, V., Mardis, E. R., and Gordon, J. I. (2006). An obesity-associated gut microbiome with increased capacity for energy harvest. Nature 444, 1027-1031. doi: 10.1038/nature 05414

Ulluwishewa, D., Anderson, R. C., McNabb, W. C., Moughan, P. J., Wells, J. M., and Roy, N. C. (2011). Regulation of tight junction permeability by intestinal bacteria and dietary components. J. Nutr. 141, 769-776. doi: 10.3945/jn.110. 135657

van Es, J.H., van Gijn, M.E., Riccio, O., van den Born, M., Vooijs, M., Begthel, H., et al.(2005). Notch $/ \gamma$-secretase inhibition turns proliferative cells in intestinal crypts and adenomas into goblet cells. Nature 435, 959-963. doi: 10.1038/ nature 03659 
van Nood, E., Vrieze, A., Nieuwdorp, M., Fuentes, S., Zoetendal, E. G., de Vos, W. M., et al. (2013). Duodenal infusion of donor feces for recurrent Clostridium difficile. N. Engl. J. Med. 368, 407-415. doi: 10.1056/NEJMoa1205037

van Vliet, M. J., Harmsen, H. J., de Bont, E. S., and Tissing, W. J. (2010). The role of intestinal microbiota in the development and severity of chemotherapy-induced mucositis. PLOS Pathog. 6:e1000879. doi: 10.1371/ journal.ppat.1000879

Veldhuizen, E. J., Hendriks, H. G., Hogenkamp, A., Van Dijk, A., Gaastra, W., Tooten, P. C., et al. (2006). Differential regulation of porcine $\beta$-defensins 1 and 2 upon Salmonella infection in the intestinal epithelial cell line IPI-2I. Vet. Immunol. Immunopathol. 114, 94-102. doi: 10.1016/j.vetimm.2006.07.012

Vondruskova, H., Slamova, R., Trckova, M., Zraly, Z., and Pavlik, I. (2010). Alternatives to antibiotic growth promoters in prevention of diarrhoea in weaned piglets: a review. Vet. Med. 55, 199-224.

Walker, A. (2010). Breast milk as the gold standard for protective nutrients. J. Pediatr. 156(2 Suppl), S3-S7. doi: 10.1016/j.jpeds.2009.11.021

Wang, J., Han, M., Zhang, G., Qiao, S., Li, D., and Ma, X. (2016). The signal pathway of antibiotic alternatives on intestinal microbiota and immune function. Curr. Protein Pept. Sci 17, 785-796. doi: 10.2174/1389203717666160526123351

Wlodarska, M., Willing, B., Keeney, K. M., Menendez, A., Bergstrom, K. S., Gill, N., et al. (2011). Antibiotic treatment alters the colonic mucus layer and predisposes the host to exacerbated Citrobacter rodentium-induced colitis. Infect. Immun. 79, 1536-1545. doi: 10.1128/IAI.01104-10
Wu, G. D., Chen, J., Hoffmann, C., Bittinger, K., Chen, Y. Y., Keilbaugh, S. A., et al. (2011). Linking long-term dietary patterns with gut microbial enterotypes. Science 334, 105-108. doi: 10.1126/science.1208344

Xiao, D., Tang, Z., Yin, Y., Zhang, B., Hu, X., Feng, Z., et al. (2013). Effects of dietary administering chitosan on growth performance, jejunal morphology, jejunal mucosal sIgA, occludin, claudin-1 and TLR4 expression in weaned piglets challenged by enterotoxigenic Escherichia coli. Int. Immunopharmacol. 17, 670-676. doi: 10.1016/j.intimp.2013.07.023

Xu, R. J., Mellor, D. J., Tungthanathanich, P., Birtles, M. J., Reynolds, G. W., and Simpson, H. V. (1992). Growth and morphological changes in the small and the large intestine in piglets during the first three days after birth. J. Dev. Physiol. 18, $161-172$.

Conflict of Interest Statement: The authors declare that the research was conducted in the absence of any commercial or financial relationships that could be construed as a potential conflict of interest.

Copyright (C) $2018 \mathrm{Hu}$, Geng, Li, Cheng, Fu, Yue and Han. This is an open-access article distributed under the terms of the Creative Commons Attribution License (CC BY). The use, distribution or reproduction in other forums is permitted, provided the original author(s) or licensor are credited and that the original publication in this journal is cited, in accordance with accepted academic practice. No use, distribution or reproduction is permitted which does not comply with these terms. 